\title{
Anonychia-microcephaly syndrome
}

INSERM

\section{Source}

INSERM. (1999). Orphanet: an online rare disease and orphan drug data base. Anonychiamicrocephaly syndrome. ORPHA:1094

Anonychia-microcephaly syndrome is a multiple congenital anomaly disorder characterized by anonychia cong enita totalis and microcephaly, and normal intelligence along with some minor anomalies including single transverse palmar creases, fifth-finger clinodactyly and widely-spaced teeth. 